Research Paper

\title{
Evaluation of Date Extract on Nerve Conduction Velocity in Male Rats
}

\author{
Hossein Ali Ebrahimi ${ }^{\text {* }}$ (D), Mandana Jafari ${ }^{2}$ (i), Narges Khanjani ${ }^{1}$ (D), Najmeh Moradi
}

1. Neurology Research Center, Kerman University of Medical Sciences, Kerman, Iran

2. Pharmaceutics Research Institute of Neuropharmacology, Kerman University Medical Sciences, Kerman, Iran.

3. Afzalipour Medical Faculty Kerman, University of Medical Sciences, Kerman, Iran.

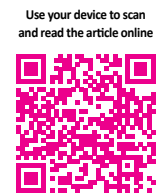

Citation Ebrahimi, H. A., Jafari, M., Khanjani, N., \& Moradi, N. (2021). Evaluation of Date Extract on Nerve Conduction Velocity in Male Rats. Basic and Clinical Neuroscience, 13(3), 385-392. http://dx.doi.org/10.32598/ben.2021.878.2

doi $h$ http://dx.doi.org/10.32598/ben.2021.878.2

\section{(c) (i) (\$)}

Article info:

Received: 08 Nov 2017

First Revision: 15 Mar 2020

Accepted: 25 Aug 2020

Available Online: 01 May 2022

Keywords:

Date extract, Nerve conduction velocity, Male rats, Sciatic nerve

\section{AB S T RACT}

Introduction: Neuropathy is a condition in which the Peripheral Nervous System (PNS) is disordered. Studying the effects of antioxidants on the performance improvement of this system is vital. This study aimed to investigate the effects of date extract on Nerve Conduction Velocity (NCV), Distal Motor Latency (DML), and wave height of the sciatic nerve in male rats.

Methods: This laboratory study used 24 male Wistar rats weighing 250-300 g, divided into the test and control groups. The test group received $10 \%$ date extract daily, at $4 \mathrm{~mL} / \mathrm{kg}$ of body weight, for three weeks. In the beginning, nerve Conduction Velocity (NCV), Distal Motor Latency (DML), and wave height of the sciatic nerve were examined in all animals and reexamined for NCV three weeks later. P-values lower than 0.05 were considered significant.

Results: Sciatic NCV and wave height were significantly increased; however, compared to the control group, DML of the knee significantly declined in the test group.

Conclusion: The compositions of date extract accelerate electrical signal transmission.

* Corresponding author:

Hossein Ali Ebrahimi, MD.

Address: Neurology Research Center, Kerman University of Medical Sciences, Kerman, Iran.

Tel: +98 (913) 1404513

E-mail:hebrahimi@kmu.ac.ir 


\section{Highlights}

- Irreparable damages to the Peripheral Nervous System (PNS) are major problems in societies.

- Different therapeutic methods have been adopted for peripheral nerve repair

- According to FAO, the production and use of dates are rising.

- Dates are used in traditional medicine for curing hoarseness, paralysis, backache, and rheumatic pains.

\section{Plain Language Summary}

Dates are highly important in our nutrition. There have been studies on the positive antioxidative effects of date extract in preventing diabetic neuropathy. Dates are used in traditional medicine for curing hoarseness, paralysis, backache, and rheumatic pains, among others. The importance of dates is derived from their rich compositions of carbohydrates, salts and minerals, dietary fiber, vitamins, fatty acids, amino acids, and proteins. Different therapeutic methods have been adopted for PNS, still, 50\% of these damages become permanent and cause disability. Date palms are in the palm family native to Iran, and found in relatively tropical regions.Dates are used in traditional medicine for curing hoarseness, paralysis, backache, and rheumatic pains, among others. In short, the compositions of date extract accelerate electrical signal transmission.

\section{Introduction}

ne of the issues facing human societies, whether industrial or nonindustrial, is the irreparable damage to the peripheral nervous system (PNS). Studies have reported that, in Mumbai, damages to the PNS have been reported in $2.4 \%$ of people and $8 \%$ of individuals over 55

(Azhary, Farooq, Bhanushali, Majid, \& Kassab, 2010; Hughes, 2002; Martyn \& Hughes, 1997).

However, different therapeutic methods have been adopted for peripheral nerve repair; still, $50 \%$ of these damages become permanent and cause disability. However, unlike the Central Nervous System (CNS), peripheral nerve fibers can regenerate and innervate distal targets, a process that starts almost immediately after the damage. Knowing this, it can be hypothesized that understanding the basic regulatory mechanisms for axon regeneration intended to regulate neuronal growth may help introduce new methods to accelerate and enhance nerve regeneration (Samuels, Ropper, \& Klein, 2014).

Dates have played a major role in human life since 7000 years ago, especially for the Arabs. They grow in arid and semi-arid regions (Kanarek, Mandillo, \& Wiatr, 2001). According to the Food and Agriculture Organization of the United Nations (FAO), the production, use, and industrial application of dates are rising (Tandon,
Srivastava, Nagpal, Khosla, \& Singh, 2000). Dates are mostly produced in Egypt, followed by Saudi Arabia, Iran, UAE, and Algeria (Chandrasekaran \& Bahkali, 2013). Date palms are cylindrical unbranched trunks, and the entire length of the stem is also free of leaves. They only let out large leaves and pinnate leaflets on the crown at the top. Date palms are in the palm family 'Palmacae,' native to Iran, and found in relatively tropical regions of Kermanshah, Khuzestan, Fars, Kerman, Hormozgan, and Sistan and Baluchestan. Dates most likely have medicinal properties that are still unknown (Cook $\&$ Furr, 1952). Recent reports concern the antioxidative, liver protection, anti-mutagenic, anti-tumoral, anti-inflammatory, anti-bacterial, and, probably, anti-diarrheal properties as well as protection of the digestive system for this plant (Allaith, 2009; Chevallier, 1996; Hammad \& Sallal, 2002; Saafi et al., 2011). Date palms are in the palm family 'Palmacae,' bearing the scientific name Phoenix dactylifera (Samuels, et al, 2014).

Dates are used in traditional medicine for curing hoarseness, paralysis, backache, and rheumatic pains, among others. Dates are highly important in our nutrition. The importance of dates is derived from their rich composition: carbohydrates (make up $50 \%-60 \%$ of the dried fruits) (Alkaabi et al., 2011), salts and minerals, dietary fiber, vitamins, fatty acids, amino acids, and proteins. Accordingly, from many aspects, dates are considered an ideal meal. Dates also boost various useful properties, including antioxidative, anti-mutagenic, 
anti-tumoral, anti-bacterial, and digestive system protection effects (Chevallier, 1996; Hammad \& Sallal, 2002). They also have protective effects on the neurons, owing to compounds like polyphenol and melatonin (Vayalil, 2002). The anti-hepatotoxic effects of date extract on rat liver have already been studied (Zangiabadi et al., 2011). Studies have addressed and approved the antioxidative and anti-mutagenic effects of different species of dates (Allaith, 2009; Saafi et al., 2011). There have been studies on the positive antioxidative effects of date extract in preventing diabetic neuropathy. In a study date extract treatment shows efficacy for preventing diabetic deterioration and for improving pathological parameters of diabetic neuropathy in rats, as compared with control groups (Mansouri, Embarek, Kokkalou, \& Kefalas, 2005; Shabani, Zangiabadi, \& Asadi-Shekaari, 2013). A study on the effects of the watery extract on pain in rats has reported increased pain.

\section{Materials and Methods}

\section{Animals and lab protocols}

Care of laboratory animals was based on the Guide for the Care and Use of Laboratory Animals at Kerman Neuroscience Research Center of Kerman University of Medical Sciences, approved by the Animal Ethics Committee.

This study used male Wistar rats weighing 250 to 300 g. The rats received standard diets during the study and were kept in the animal lab under special conditions, away from pathogenic agents at a fixed temperature and normal environment (12:12 hours, light: dark cycle). For statistical accuracy, intensive care was applied to minimize pain in animals and reduce the number of animals.

Animals in this study were divided into control and experimental groups. The control group received daily food and water without date extract, and the test group received food and water plus $10 \%$ date extract, $4 \mathrm{~mL} /$ $\mathrm{kg}$ for three weeks in the daily water intake. Both at the beginning and the end of the intervention, the weight of all the animals was measured along with their nerve conduction velocity $\mathrm{NCV}$.

\section{Extracting method}

For preparing the watery date extract, after procurement of fresh Mazafati dates from Bam orchards, the pits were removed, then $200 \mathrm{~g}$ of the date flesh was soaked in $2000 \mathrm{~mL}$ of distilled water for 48 hours, and later on, completely mixed by a mixer. The resulting mix was centrifuged at $4000 \mathrm{rpm}$ for $20 \mathrm{~min}$, at $4^{\circ} \mathrm{C}$. Then, the solution in the upper area of the tube was removed from the remaining sediment and kept at $-20^{\circ} \mathrm{C}$ until further use. By conducting electrodiagnostic assessments, data collection on the control and experimental rats was done by a person blind to the experimental conditions.

\section{$\mathrm{NCV}$ assessment and recording}

Three weeks after commencing the oral intake of date extract, the animals were anesthetized using ketamine/ xylazine $(50 / 20 \mathrm{mg} / \mathrm{kg})$ solution. The environmental temperature was set to $25^{\circ} \mathrm{C} \pm 1{ }^{\circ} \mathrm{C}$ throughout the study. After shaving the legs of the animals using bipolar electrodes of AD-Instruments ML856 Power-Lab, the sciatic nerve was stimulated at the knee and ankle, and immediately after the stimulation, the muscle's nerve potential was recorded by the unipolar electrodes attached to the sole of the hind paw. The obtained records were the biphasic responses with an initial $\mathrm{M}$ wave created by the stimulation of motor fibers.

$\mathrm{NCV}($ Mean $\pm \mathrm{SD})$ was calculated as the ratio of the distance between the two stimulation locations $(\mathrm{mm})$ to the recording time difference between the two stimulated regions $(\mathrm{m} / \mathrm{s})$. Latency $(\mathrm{Mean} \pm \mathrm{SD})$ was calculated as the time stimulation to recording (millisecond). The height of waves (Mean $\pm \mathrm{SD})$ was calculated to millivolts. The findings analyzed by SPSS software .

\section{Results}

The experiment was conducted on 24 male Wistar rats. The Mean \pm SD weights of the rats were $268.3 \pm 8.3$ gr prior to and $275.8 \pm 11.6 \mathrm{~g}$ after date extract intake, which is not significant $(\mathrm{P}=0.075)$.

The control group, not receiving date extract, had an Mean \pm SD weight of $266.25 \pm 10.2$ gr at the beginning and $279.5 \pm 11.7 \mathrm{gr}$ at the end of the experiment, yet, although significant, the weight gain difference between the two groups was not significant $(\mathrm{P}=1)$ (Table 1).

NCV significantly increased from $47.2 \pm 11.5 \mathrm{~m} / \mathrm{s}$ before date extract intake to $54.1 \pm 15.2 \mathrm{~m} / \mathrm{s}$ afterward $(\mathrm{P}<0.001)$. $\mathrm{NCV}$ also increased in the control group: $37.2 \pm 7.6 \mathrm{~m} / \mathrm{s}$ at the beginning of the project and $39.6 \pm 8.5 \mathrm{~m} / \mathrm{s}$ at the end, indicating a significant difference $(\mathrm{P}=0.001)$. The increased NCV examined in the two groups, i.e., $2.4 \pm 2$ $\mathrm{m} / \mathrm{s}$ in the control group and $6.5 \pm 4.1 \mathrm{~m} / \mathrm{s}$ in the test group shows a significant difference $(\mathrm{P}=0.008)$ (Figure 1$)$. The difference in distal motor latency (DML) in knee and ankle of the cases of test and control groups at the be- 


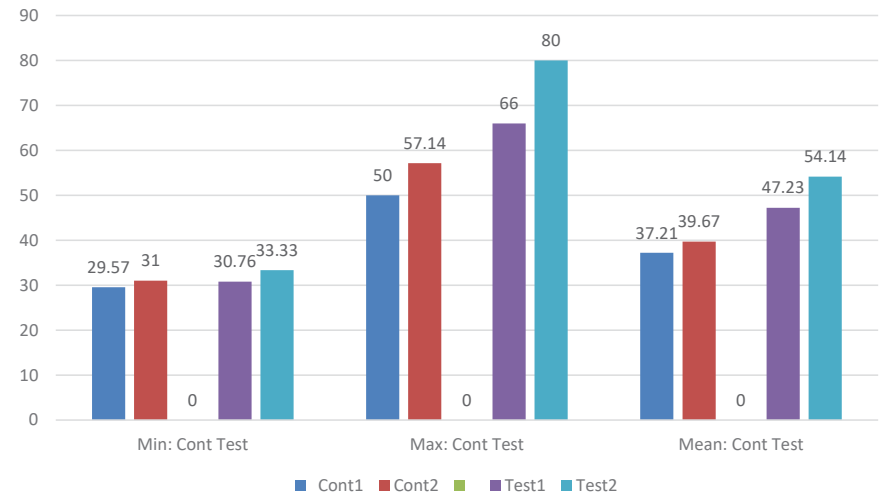

NEUR SCIENCE

Figure 1. Nerve conduction velocity $(\mathrm{m} / \mathrm{s})$ of sciatic nerve (12 rats) in the control and test groups before and after the intake of date extract

ginning and end of the experiment was not significant $(\mathrm{P}=0.473)$ (Table 2).

The height of the waves in the ankle of the control group was $2.3 \pm 2.2 \mathrm{mV}$ at the beginning and $2.8 \pm 2 \mathrm{mV}$ at the end $(\mathrm{P}=0.214)$. The height of the waves $\mathrm{n}$ the knees of the control group animals was $1.6 \pm 1 \mathrm{mV}$ at the beginning and $1.8 \pm 1 \mathrm{mV}$ at the end $(\mathrm{P}=0.267)$. On the other hand, the height of the waves in the ankle of the test group animals was $2.3 \pm 2.1 \mathrm{mV}$ at the beginning and $5.3 \pm 2.4 \mathrm{mV}$ at the end $(\mathrm{P}=0.001)$. The height of the waves in the knee of test group animals was $2.9 \pm 2.6 \mathrm{mV}$ at the beginning and $4 \pm 1.2 \mathrm{mV}$ at the end $(\mathrm{P}=0.181)$. The difference in the height of waves in the ankles of animals in the control and test group was significant: 0.8 for the control and 3 for the test group $(\mathrm{P}=0.020)$. The difference in the height of waves in the knees of animals in the control and test groups was also significant: 0.4 for the control and 1.1 for the test group $(\mathrm{P}=0.001)$ (Figure 2).

\section{Discussion}

According to our investigations, this study is the first to address the effects of date extract on NCV. The results of the present study show for the first time that watery date extract considerably increases NCV. Furthermore, our results suggest that these effects are induced by accelerated myelination in the neurological unit. Conduction velocity in the CNS and PNS is an agent of myelination, as NCV is slower in unmyelinated fibers than in the myelinated ones (Chevallier, 1996). Myelin is a multi-layer protein and lipid composition formed by the glial cell plasma membrane.

Unlike nerve cells, the remyelination speed is fast and a matter of minutes, independent of the growing age, accelerated myelination. Also, increased myelin diameter is effective in a higher NCV (Vayalil, 2002).

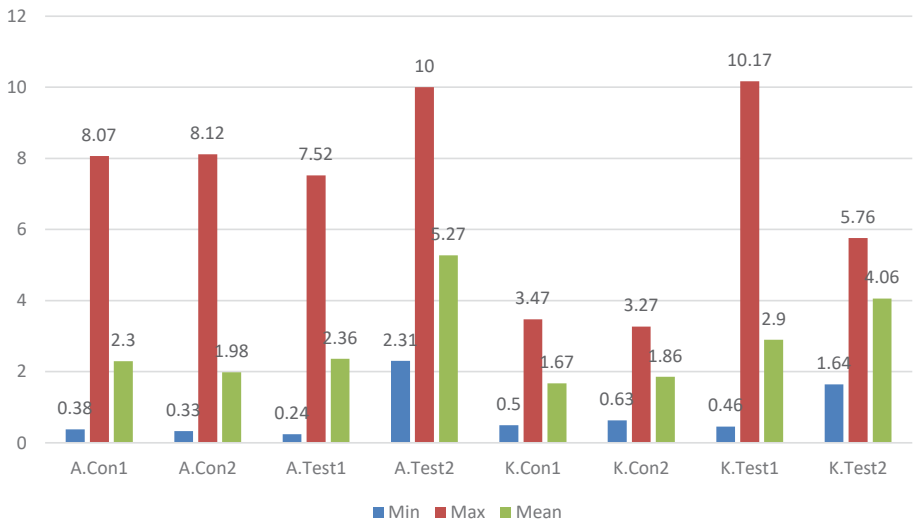

Figure 2. Amplitude $(\mathrm{mV})$ of sciatic nerve in the test and control groups before and after study

1: before intake, 2: after intake. 
Table 1. Weight of rats $(\mathrm{g})$ before and after date extract intake $(\mathrm{n}=12)$

\begin{tabular}{|c|c|c|c|}
\hline Weight & Mean $\pm S D$ & Min & Max \\
\hline Test 1 & $268.33 \pm 8.348$ & 260 & 280 \\
\hline Test 2 & $275.83 \pm 11.64$ & 255 & 295 \\
\hline Cont 1 & $266.25 \pm 10.25$ & 250 & 280 \\
\hline Cont 2 & $279.58 \pm 11.76$ & 260 & 300 \\
\hline
\end{tabular}

In this study, the authors observed an increased wave height in the ankles of subjects in the test group after intake of watery date extract, which can be due to an increased myelin sheath activity, though this increase is mostly owed to the increased axonal activity.

The two latter findings are derived from the enhanced neural activity in transmitting electrical signals from neurons to the muscle. An activity that is an agent of axonal diameter, which may change drastically in three weeks, and is more related to increased myelin thickness or activity.

The effect of myelin in signal transmission is realized through several major channels. The myelin sheath insulates the axon and inhibits current leakage out of the neural route and, thus, keeps signal strength from weakening. Further, there are the nodes of Ranvier in the periodic gaps in the myelin, which act as springboards in transmitting the signals. Date extract compositions may also accelerate the ionic activity (Allaith, 2009).
The other activities of date palm fruit are effect on bile and fatty acids. In two studies establish that an extract made from date palm fruit acts as a co-agonist ligand for Farnesoid X Receptor (FXR), a nuclear receptor critical for maintaining bile acid, cholesterol, and triglyceride homeostasis (Stroeve et al., 2010; Zhang \& Edwards, 2008). In other study shows that dates contain bioactive compounds which exert FXR-mediated regulatory effects that may contribute to the underlying molecular mechanism involved in the triglyceride-lowering action of dates. Additionally, this study identifies a new potential intestinally-mediated mechanism by which poorlybioavailable polyphenols from dates could affect blood lipid levels without being absorbed systemically (Alfaro-Viquez et al., 2018).

Watery date extract can affect myelin repair and growth. Making up almost half of the date sugar, fructose affects the creation of fat storage in prone areas, also, owing to the many fibers of the date, it can dispose of cholesterol (Zangiabadi et al., 2011). Myelin can be one of these appropriate sites. It is a lipid tissue composed of components with

Table 2. Distal latency $(\mathrm{m} / \mathrm{s})$ of sciatic nerve of 12 rats at knee and ankle sites before and after intake of date extract in the test and control groups $(\mathrm{n}=12)$

\begin{tabular}{|cccc}
\hline Distal Latency & Mean \pm SD & Min & Max \\
\hline Test Knee 1 & $2.98 \pm 0.15$ & 2.8 & 3.3 \\
\hline Test Ankle 1 & $2.07 \pm 0.18$ & 1.8 & 2.5 \\
\hline Test Knee 2 & $3.05 \pm 0.12$ & 2.8 & 3.2 \\
\hline Test Ankle 2 & $2.15 \pm 0.13$ & 1.6 & 3.2 \\
\hline Cont Knee 1 & $2.84 \pm 0.14$ & 2.7 & 2.1 \\
\hline Cont Ankle 1 & $1.75 \pm 0.23$ & 1.4 & 3.3 \\
\hline Cont Knee 2 & $2.99 \pm 0.19$ & 2.7 & 2.2 \\
\hline Cont Ankle 2 & $1.94 \pm 0.21$ & 1.5 & 3.2 \\
\hline
\end{tabular}


rapid regenerative and rotating capabilities, in some cases, within a few minutes. It may also affect the ion transmission of the nodes of Ranvier (Alkaabi et al., 2011).

The authors observed a significant increase in NCV in the control group, far less than in the test group. This increase is due to the growth of the myelin sheath, which is never-ending, though slows down after puberty. Increased NCV in the control group one month later is justifiable, as myelin synthesis is independent of age (Vayalil, 2002).

In mild lesions of the PNS, initial unpleasant pains are often observed spontaneously or in response to non-painful sensory stimulation (Alkaabi et al., 2011). We believe the impaired transmission of neural signals induces this unpleasant feeling. This condition can be treated using proper medications, which help improve the activity of the PNS, both in the myelin sheath and the axon, and probably prevent the progress of such lesions (Shekaari et al., 2008).

\section{Conclusion}

The compositions of date extract accelerate electrical signal transmission.

\section{Ethical Considerations}

\section{Compliance with ethical guidelines}

The current project was approved by the Neurology Research Center, Kerman University of Medical Sciences.

\section{Funding}

This research did not receive any grant from funding agencies in the public, commercial, or non-profit sectors.

\section{Authors' contributions}

All authors equally contributed to preparing this article.

\section{Conflict of interest}

The authors declared no conflict of interest.

\section{Acknowledgments}

I would like to extend my appreciation to those who assisted us in all the stages of the project, Mohammad Sheybani, Sheikhshoaei, Jam, and all the kind staff of Kerman Neuroscience Research Center.

\section{References}

Martyn, C. N., \& Hughes, R. A. (1997). Epidemiology of peripheral neuropathy. Journal of Neurology, Neurosurgery, and Psychiatry, 62(4), 310-318. [DOI:10.1136/jnnp.62.4.310] [PMID] [PMCID]

Hughes, R. A. C. (2002). Peripheral neuropathy. BMJ, 324(7335), 466-469. [DOI:10.1136/bmj.324.7335.466] [PMID] [PMCID]

Azhary, H., Farooq, M. U., Bhanushali, M., Majid, A., \& Kassab, M. Y. (2010). Peripheral Neuropathy: Differential Diagnosis and Management. American Family Physician, 81(7), 887-892. [PMID]

Samuels, M. A., Ropper, A. H., \& Klein, J. (2014). Adams and Victor's principles of neurology. New York: McGraw-Hill Companies. https://books.google.com/books/about/Adams_and_Victor_s_Principles_of_Neurolo.AAJ

Kanarek, R. B., Mandillo, S., \& Wiatr, C. (2001). Chronic sucrose intake augments antinociception induced by injec of $\mathrm{mu}$ but not kappa opioid receptor agonists into the periaqueductal gray matter in male and female rat. Brain Research, 920(1-2), 97-105 [DOI:10.1016/S0006-8993(01)03039-6]

Tandon, M., Srivastava, R. K., Nagpal, R. K., Khosla, P., \& Singh, J. (2000). Differential modulation of nociceptive responses to mu and kappa opoid receptor directed drugs by blood glucose in experimentally induced diabetes rats. Indian Journal of Experimental Biology, 38(3), 242-248. [PMID]

Chandrasekaran, M., \& Bahkali, A. H. (2013). Valorization of date palm (Phoenix dactylifera) fruit processing by-products and wastes using bioprocess technology. Saudi Journal of Biological Sciences, 20(2), 105-20. [DOI:10.1016/j.sjbs.2012.12.004] [PMID] [PMCID]

COOK, J. A., \& FURR, J. R. (1952). Sugars in the fruit of soft, semidry and dry commercial date varieties. Michigan: Bible. https://www.cabdirect.org/cabdirect/abstract/19550302067

Chevalier, A. (1996). The encyclopedia of medicinal plants. New York: DK Pub. https://books.google.com/books?id=EbLuA AAAMAAJ\&dq $=$ The + encyclopedia + of + medicinal + plantsI

Hammad, M., \& Sallal, A. K. (2002). Effects of date extract on growth and hemolylitic of streptococcus pyogen. The New Microbiologica, 25(4), 495-497. [PMID]

Saafi, E. B., Louedi, M., Elfeki, A., Zakhama, A., Najjar, M. F., \& Hammami, M., et al. (2011). Protective effect of date palm fruit extract (Phoenix dactylifera L.) on dimethoate induced-oxidative stress in rat liver. Experimental and Toxicologic Pathology, 63(5), 433-441. [DOI:10.1016/j.etp.2010.03.002] [PMID]

Allaith, A. A. A. (2008). Antioxidant Activity of Bahrain, DatePalm (Phoenix dactylifera L.) Fruit of Various Cultivars. International Journal of Food Science \& Technology, 43(6), 1033-1040. [DOI:10.1111/j.1365-2621.2007.01558.x]

Alkaabi, J. M., Al-Dabbagh, B., Ahmad, S., Saadi, H. F., Gariballa, S., \& Al Ghazali, M. (2011). Glycemic indices of five varieties of dates in healthy and diabetic subjects. Nutrition Journal, 10, 59. [DOI:10.1186/1475-2891-10-59] [PMID] [PMCID] 
Vayalil P. K. (2002). Antioxidant and antimutagenic properties of aqueous extract of date fruit (Phoenix dactylifera L. Arecaceae). Journal of agricultural and food chemistry, 50(3), 610-617. [DOI:10.1021/jf010716t] [PMID]

Zangiabadi, N., Asadi-Shekaari, M., Sheibani, V., Jafari, M., Shabani, M., \& Asadi, A. R., et al. (2011). Date fruit extract is a neuroprotective agent in diabetic peripheral neuropathy in streptozotocin-induced diabetic rats: A multimodal analysis. Oxidative Medicine and Cellular Longevity, 2011,976948. [DOI:10.1155/2011/976948] [PMID] [PMCID]

Mansouri, A., Embarek, G., Kokkalou, E., \& Kefalas, P. (2005). Phenolic profile and antioxidant activity of the Algerian ripe date palm fruit (Phoenix dactylifera). Food Chemistry, 89(3), 411-420. [DOI:10.1016/j.foodchem.2004.02.051]

Shabani, M., Zangiabadi, N., \& Asadi-Shekaari, M. (2013). Evidence for positive effects of date extract that attenuates thermal hyperalgesia in a diabetic rat model of neuropathic pain. Neuroscience \& Medicine, 4, 16-22. [DOI:10.4236/ nm.2013.41003]

Stroeve, J. H., Brufau, G., Stellaard, F., Gonzalez, F. J., Staels, B., \& Kuipers, F. (2010). Intestinal FXR-mediated FGF15 production contributes to diurnal control of hepatic bile acid synthesis in mice. Laboratory Investigation, 90(10), 1457-1467. [DOI:10.1038/labinvest.2010.107] [PMID] [PMCID]

Zhang, Y., \& Edwards, P. A. (2008). FXR signaling in metabolic disease. FEBS Letters, 582(1), 10-18. [DOI:10.1016/j.febslet.2007.11.015] [PMID]

Alfaro-Viquez, E., Roling, B. F., Krueger, C. G., Rainey, C. J., Reed, J. D., \& Ricketts, M. L. (2018). An extract from date palm fruit (Phoenix dactylifera) acts as a co-agonist ligand for the nuclear receptor FXR and differentially modulates FXR target-gene expression in vitro. PloS One, 13(1), e0190210. [DOI:10.1371/journal.pone.0190210] [PMID] [PMCID]

Zangiabadi, N., Asadi-Shekaari, M., Sheibani, V., Jafari, M., Shabani, M., \& Asadi, A. R., et al. (2011). Date fruit extract is a neuroprotective agent in diabetic peripheral neuropathy in streptozotocin-induced diabetic rats: A multimodal analysis. Oxidative Medicine and Cellular Longevity, 2011, 976948. [DOI:10.1155/2011/976948] [PMID] [PMCID]

Shekaari, A., Sheibani, V., Ebrahimi, H., Rismanchian, M., Kalantari Pour, T., \& Afarinesh, M. R. (2008). Effect of long term consumption of aqueous date fruit extract on analgesia response in male rat. Journal of Babol University of Medical Sciences, 9(6), 7-12. http://jbums.org/article-1-2487-en.html 
This Page Intentionally Left Blank 